\title{
Transparent MXene-Polymer Supercapacitive Film Deposited Using RIR-MAPLE
}

\author{
Alec Ajnsztajn ${ }^{1,+}{ }^{\dagger}$, Spencer Ferguson ${ }^{2,+}{ }^{\dagger}$ James O. Thostenson ${ }^{2}$, Edgard Ngaboyamahina ${ }^{2}$, \\ Charles B. Parker ${ }^{2} \mathbb{D}$, Jeffrey T. Glass ${ }^{2,3, *}$ and Adrienne D. Stiff-Roberts $2,3, * \mathbb{D}$ \\ 1 Department of Mechanical Engineering and Materials Science, Duke University, Durham, NC 27708, USA; \\ alec.ajnsztajn@duke.edu \\ 2 Department of Electrical and Computer Engineering, Duke University, Durham, NC 27708, USA; \\ spencer.ferguson@duke.edu (S.F.); james.thostenson@duke.edu (J.O.T.); \\ Edgard.Ngaboyamahina@duke.edu (E.N.); charles.parker@duke.edu (C.B.P.) \\ 3 University Program in Materials Science and Engineering, Duke University, Durham, NC 27708, USA \\ * Correspondence: jeff.glass@duke.edu (J.T.G.); adrienne.stiffroberts@duke.edu (A.D.S.-R.) \\ + Authors contributed equally to this work.
}

Received: 31 January 2020; Accepted: 25 February 2020; Published: 27 February 2020

\begin{abstract}
In this work, resonant infrared matrix-assisted pulsed laser evaporation (RIR-MAPLE), a novel deposition technique, was used to produce a transparent composite electrode of polyflourene (PFO) and two-dimensional (2D) $\mathrm{Ti}_{3} \mathrm{C}_{2} \mathrm{~T}_{\mathrm{x}}$ nanosheets, which are part of the broader MXene family of transition metal carbides and nitrides. This deposition technique offers a facile way to vary film composition in polymer/polymer and polymer/nanoparticle films. Through this method, composite PFO and MXene films were studied across six different compositions, enabling the identification of a film composition that exhibited excellent charge storage (above $10 \mathrm{mF} / \mathrm{cm}^{2}$ ) and transparency (over $75 \%$ transmittance) when used as a supercapacitor electrode material. Thus, RIR-MAPLE shows promise as a controllable and facile deposition technique for organic/inorganic composite films for use in transparent supercapacitors, as well as in other energy storage applications.
\end{abstract}

Keywords: RIR-MAPLE; PFO; MXene; transparent capacitive electrode

\section{Introduction}

Composite films offer a great advantage to improve material properties that can lead to increased device performance. Depositing very thin composite films using traditional solution processing approaches is a challenge, due to differences in material solubility [1-3]. As a result, composite materials are often not compatible with traditional solution processing techniques [1], motivating the need to develop novel approaches to deposit composite films. Supercapacitor electrode materials are one application that can benefit from being deposited as a thin composite film because it would allow for the creation of films that combine energy and power dense storage with other properties, such as high optical transmittance and/or flexibility [1,4,5]. Additionally, as consumer electronics move toward optically transparent devices, supercapacitors present a promising energy storage technology, due to their combination of high transmittance and energy density, properties that are not currently met by conventional batteries, capacitors, and other electrochemical energy storage devices [6,7].

While multiple metal- and non-metal-based transparent supercapacitor electrode materials have been investigated, almost all reported materials have a capacitance of less than $1 \mathrm{~F} / \mathrm{cm}^{2}$ [8]. In many cases, the low capacitance is due to the use of a single material. In general, a tradeoff exists between optical transmittance and capacitance [4]. To achieve transparency, the thickness of the films must be very small $(\sim<300 \mathrm{~nm})$; however, this very thin nature leads to an increase in electrode resistance, 
and this diminishes its capacitance [4]. Composite films are an ideal choice for transparent energy storage because they enable multi-functional films with both a capacitive material and a transparent conductive material. While composite materials have been shown to help increase the capacitive behavior and transparency of supercapacitor electrodes, the film properties are limited by solution processing deposition techniques [1,9]. Specifically, there are restrictions on the materials that can be combined, it can be difficult to deposit homogenous films, and control over material composition is diminished. Thus, a novel approach is needed to create better composite films for transparent supercapacitor electrodes.

One such novel approach is RIR-MAPLE (resonant infrared matrix-assisted pulsed laser evaporation) [10]. RIR-MAPLE is particularly useful for creating composite organic/inorganic films comprising materials that require incompatible solvents and cannot be deposited using traditional solution processing techniques. In addition, RIR-MAPLE is a gentle physical vapor deposition technique that is appropriate for organic materials [11] and nanoparticles [12] because it avoids high-energy sources that induce damage in the target materials. The process uses a low-energy erbium: yttrium-aluminum-garnet infrared (Er:YAG) laser with a peak wavelength at $2.94 \mu \mathrm{m}$ to irradiate a frozen target solution $[11,13]$. The laser wavelength is resonant with hydroxyl bonds that must be present in the target matrix (or solvent), such that the matrix is evaporated and the target material is released and transferred to the substrate. Typically, organic materials are deposited from an emulsion that is formed (using minimal surfactant) between a water matrix and a nonpolar solvent that contains the dissolved organic material $[14,15]$. The emulsion is frozen, and the water-ice matrix is evaporated by the laser, allowing the organic material to transfer to the substrate (maintaining the morphology it has in the frozen emulsion). Nanoparticles are deposited from suspensions in water that are frozen in the same manner as the emulsion [16]. Polymer/nanoparticle composite films deposited by RIR-MAPLE have exhibited minimal phase segregation compared to other methods of nanocomposite deposition $[17,18]$. In addition, RIR-MAPLE has recently been implemented in the fabrication of organic/inorganic metal halide perovskite solar cells, further demonstrating its versatility and suitability for hybrid organic/inorganic material systems $[19,20]$.

In this paper, two-dimensional (2D) titanium carbide $\left(\mathrm{Ti}_{3} \mathrm{C}_{2} \mathrm{~T}_{\mathrm{x}}\right)$ nanosheets, a member of the recently discovered MXene family [21], were combined with polyflourene (PFO) for study as a transparent supercapacitor electrode material, using RIR-MAPLE as the deposition technique. $2 \mathrm{D} \mathrm{Ti}_{3} \mathrm{C}_{2} \mathrm{~T}_{\mathrm{x}}$ nanosheets were chosen to provide high capacitance [21-23], while PFO was chosen to improve optical transparency, due to its high transmittance in visible light [24]. It is important to note that PFO has been used previously as a composite supercapacitor electrode material, and PFO has been deposited using emulsion-based RIR-MAPLE [25-27]. However, $2 \mathrm{D} \mathrm{Ti}_{3} \mathrm{C}_{2} \mathrm{~T}_{\mathrm{x}}$ nanosheets are best dispersed in polar solvents, which are not compatible with the solubility of PFO. Thus, solution-based deposition (i.e., spin coating) of composite thin films with both materials is challenging. In contrast, RIR-MAPLE allows for concurrent deposition through the use of a partitioned, rotating target, comprising separate mixtures for the PFO and $\mathrm{Ti}_{3} \mathrm{C}_{2} \mathrm{~T}_{\mathrm{x}}$ nanosheets, thus eliminating the need for the PFO to be soluble in the solvent used to suspend the nanosheets. Known as sequential deposition, the partitioned target is irradiated by the rastered Er:YAG laser while the target rotates to deposit the different components of the film [14]. The final film composition reflects the composition of the partitioned target. Thus, the RIR-MAPLE deposition of composite thin films comprising $\mathrm{Ti}_{3} \mathrm{C}_{2} \mathrm{~T}_{\mathrm{x}}$ nanosheets (herein referred to as MXene) in a PFO polymer matrix for application as transparent supercapacitor electrodes with significantly improved performance (i.e., capacitance and transparency) is an important demonstration of achieving a multi-functional film comprising two materials with complementary properties, yet incompatible solubility. This approach will greatly expand the materials options available to achieve state-of-the-art transparent supercapacitor electrodes. 


\section{Materials and Methods}

\subsection{Solution Preparation}

MXene flakes were created according to Ghidiu et al. [23]. First, the MAX phase ceramic precursors, in this case $\mathrm{Ti}_{2} \mathrm{AlC}_{3}$ and $\mathrm{TiC}$, were combined and ball-milled for 18 hours. The resulting powder was then heated to $1350^{\circ} \mathrm{C}$ at $5{ }^{\circ} \mathrm{C}$ per minute under Ar atmosphere, using a tube furnace, in which the powder was annealed for 2 hours. The annealed powder was then ground using a mortar and pestle and passed through a 400-mesh sieve. Concentrated $\mathrm{HCl}$ was added to distilled water to create a $6 \mathrm{M}$ solution, to which $1.98 \mathrm{~g}$ of $\mathrm{LiF}$ was added. Next, $3 \mathrm{~g}$ of $\mathrm{Ti}_{3} \mathrm{C}_{2} \mathrm{~T}_{\mathrm{x}}$ powder was added to the solution and allowed to react for $45 \mathrm{~h}$. The reacted solution was rinsed with deionized (DI) water 5 times until the $\mathrm{pH}$ of the solution was approximately $\mathrm{pH} 6$. The solution was then vacuum filtered onto cellulose membranes with a pore size of $100 \mathrm{~nm}$ to isolate the MXene powder and stored in a $\mathrm{N}_{2}$ glove box until use. MXene suspensions were created by dispersing the isolated MXene powder into DI water to a concentration of $12 \mathrm{mg} / \mathrm{mL}$. The suspension was bath-sonicated (Branson 5510, Danbury, CT, USA) for $10 \mathrm{~min}$, after which it was centrifuged for $30 \mathrm{~min}$ at $1500 \mathrm{rpm}$ (Allegra X-22R Centrifuge, Beckman Coulter, Indianapolis, IN, USA).

PFO emulsions were prepared by dissolving PFO (MilliporeSigma, Burlington, MA, USA Product \#571652) in trichlorobenzene (CAS 120-82-1) at a concentration of $20 \mathrm{mg} / \mathrm{mL}$ for $3 \mathrm{~h}$ in an inert $\mathrm{N}_{2}$ atmosphere at $60{ }^{\circ} \mathrm{C}$ while being stirred at $400 \mathrm{rpm}$. The resulting PFO solution was mixed with phenol (CAS 108-95-2) and DI water containing $0.001 \%$ by weight sodium dodecyl sulfate (SDS) (CAS 151-21-3). The resulting emulsion composition was 1:0.25:3 (trichlorobenzene/phenol/SDS/water). This mixture was shaken and stirred at $35^{\circ} \mathrm{C}$ for an additional $20 \mathrm{~min}$.

\subsection{RIR-MAPLE Deposition}

While target mixtures were prepared, the target cup within the RIR-MAPLE (PVD Products, Inc., Wilmington, MA, USA) system was pre-cooled with liquid nitrogen to $-196^{\circ} \mathrm{C}$. The partitioned target cup area was adjustable using a mold, and varied systematically to change the MXene/PFO composition within the deposited films. The prepared MXene suspension and PFO emulsion were added in $0.5 \mathrm{~mL}$ quantities to the designated regions of the target cup to ensure flash-freezing within 10-30 s. Once frozen, the chamber pressure was reduced to approximately $10^{-5}$ Torr and maintained throughout the deposition. The $2.94 \mu \mathrm{m}$ Er:YAG laser with an average fluence of $2 \mathrm{~J} / \mathrm{cm}^{2}$ was pulsed at a frequency of $2 \mathrm{~Hz}$, with a pulsed duration of $\sim 90 \mu \mathrm{s}$. Films were deposited on glass, silicon, and PET substrates for $4 \mathrm{~h}$.

For this process, we used a sequential deposition method, which allows for the deposition of two materials with different suspension/emulsion requirements. In this case, sequential deposition is required because MXene interferes with the emulsion formation of PFO. Due to the raster pattern of the laser and the rotation of the target cup, which is segmented into different sections comprising different materials, each laser pulse transfers material from either the MXene suspension or the PFO emulsion in proportion to the target composition. In this way, the composition of the film is controlled. In addition, the MXene flakes are randomly and uniformly distributed throughout the thickness and area of the film.

\subsection{Characterization}

The electrochemical characterization of MXene/PFO composite working electrodes was performed using a three-electrode cell, with an $\mathrm{Ag} / \mathrm{AgCl}$ reference electrode and a Pt-mesh counter electrode connected to a potentiostat (Biologic SP-200, Seyssinet-Pariset, France). The deposited films were characterized on conductive silicon substrates, and all electrochemical characterization was conducted through a back contact to the substrate. A $0.5 \mathrm{M} \mathrm{Na}_{2} \mathrm{SO}_{4}$ electrolyte was used, unless otherwise specified, by adding $99.9 \%$ purity $\mathrm{Na}_{2} \mathrm{SO}_{4}$ (Alfa Aesar A19890-0B, Haverhill, MA, USA) to deionized water. The effective voltage window of the electrode was found by scanning the potential window until 
cathodic and anodic peaks appeared at a current density of $0.2 \mathrm{~mA} / \mathrm{cm}^{2}$ in the cyclic voltammogram. Scanning electron microscopy (SEM) images were collected using a FEI XL30 SEM-FEG (Hillsboro, OR, USA) at an accelerating voltage of $5 \mathrm{kV}$. Energy dispersive X-ray (EDS) spectra were collected using a Bruker XFlash 4010 (Billerica, MA, USA) at $25 \mathrm{kV}$. UV-Vis transmission spectra were taken between 300 and $720 \mathrm{~nm}$ on a Shimazdu UV-3600 (Kyoto, Kyoto, Japan) with a dwell time of $1 \mathrm{~s}$, and the transmittance of the film was taken as the data point at $550 \mathrm{~nm}$ in the transmission spectra.

\section{Results and Discussion}

To understand the impact of composition (as determined by the RIR-MAPLE-partitioned target area) on the capacitive and optical properties of the deposited MXene/PFO composite films, six different compositions were deposited and named according to the MXene/PFO mixture area percentage within the target cup (Table 1). SEM imaging was performed to characterize the film morphology based on composition. As shown in Figure 1, the film morphology varied dramatically across all compositions, from just a few flakes of MXene occurring in the P50M50 composition, to large regions of MXene flakes occurring in the P25M75 and P15M85 compositions. These large regions contribute to the capacitance of the film, as having a connected network of MXene flakes allows for movement of charge through the film. With up to $15 \%$ of the film being transparent PFO, the composite film can maintain these capacitive networks but allow for the passage of light. This directly ties the film morphology to its ability as a supercapacitor electrode.

Table 1. List of electrode names tested where the percentages refer to the area of the target in resonant infrared matrix-assisted pulsed laser evaporation (RIR-MAPLE), as well as naming convention. PFO: polyfluorene.

\begin{tabular}{ccc}
\hline Electrode Name & PFO Target Area Percentage (\%) & MXene Target Area Percentage (\%) \\
\hline P100 & 100 & 0 \\
P75M25 & 75 & 25 \\
P50M50 & 50 & 50 \\
P25M75 & 25 & 75 \\
P15M85 & 15 & 85 \\
M100 & 0 & 100 \\
\hline
\end{tabular}

P100

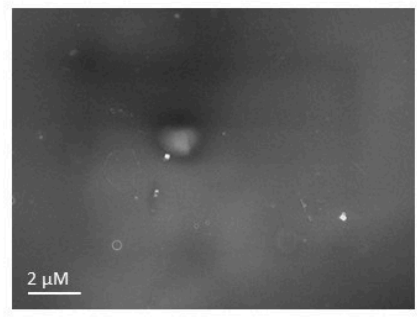

P25M75

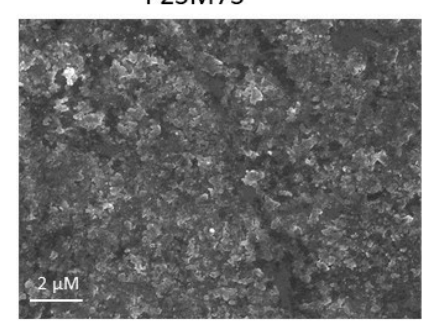

P75M25

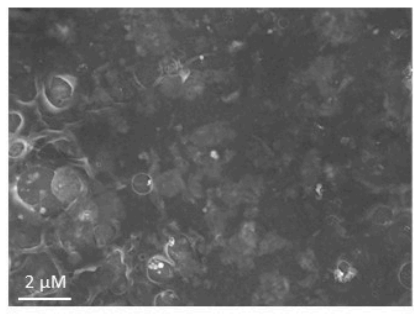

P15M85

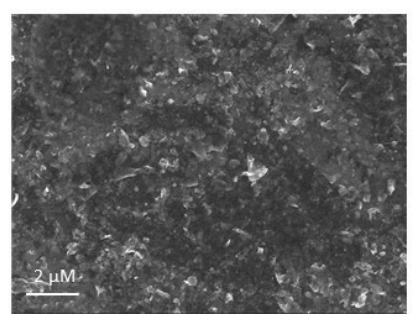

P50M50

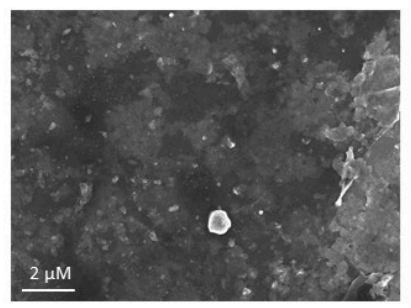

M100

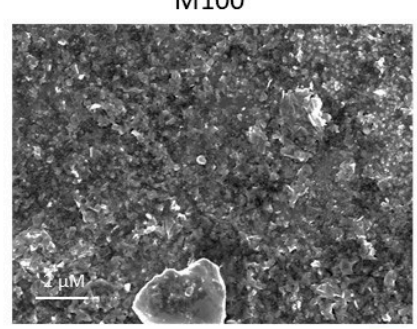

Figure 1. SEM images of different film compositions deposited in RIR-MAPLE, labeled according to Table 1. MXene flakes appear as bright white regions within each of these films, while the darker regions are the PFO matrix. The naming scheme is as follows: PxxMyy, where xx and yy indicate the area percentage within the RIR-MAPLE frozen emulsion target for PFO and MXene, respectively. 
As can be seen in Figure 1, the pure PFO (P100), MXene-rich composite (P15M85), and MXene (M100)) films have a transmittance of $\sim 80 \%, 75 \%$, and $\sim 60 \%$, respectively. The transmission spectra are shown for the visible spectrum in Figure S1 in Supplementary Materials. This trend shows that a higher amount of PFO in the composite film leads to better transmittance. Figure $2 b$ shows the cyclic voltammogram $(\mathrm{CV})$ of the P15M85 electrode. The box-like shape of the $\mathrm{CV}$ with decreasing scan rate is indicative of good capacitive behavior, though the internal resistance does appear to be high and is an area of ongoing research. The areal capacitance (C/A) was calculated from the $\mathrm{CV}$ according to the following formula [5]:

$$
\frac{C}{A}=\frac{1}{(\Delta V) \dot{V}} \int_{v}^{v+\Delta V} j d V
$$

where $\mathrm{C}$ is the nominal capacitance, $\mathrm{A}$ is the electrode area in contact with the electrolyte (determined by Image J), $v(-0.4 \mathrm{~V} \mathrm{vs} \mathrm{Ag/AgCl}$ in this work) is the starting voltage, $\Delta V$ is the potential window $(0.6 \mathrm{~V}$ in this case), $j$ is the current density, and $\dot{V}$ is the voltage sweep rate $(\mathrm{mV} / \mathrm{s})$. The capacitance was reported normalized to the sample area, because in the case of very thin films, volumetric capacitance can overstate material performance. The overestimation occurs for films below $100 \mathrm{~nm}$ because the energy storage is primarily a surface phenomenon [28]. Figure 2a shows the areal capacitance as a function of the percent area of PFO in the RIR-MAPLE target. The capacitances were all calculated at a $10 \mathrm{mV} / \mathrm{s}$ sweep rate. As can be seen in Figure 2a, both the M100 and P15M85 compositions showed excellent areal capacitance at around $20 \mathrm{mF} / \mathrm{cm}^{2}$ when deposited on conductive silicon. These promising results are enabled by the RIR-MAPLE sequential deposition that blends film components on the nanoscale without phase segregation, such that multi-functional films can be achieved [29]. This nanoscale blending increases the film conductivity, while limiting percolation that may occur in nanoparticle-based composite films, and improves optical properties due to the presence of PFO [4].

a)

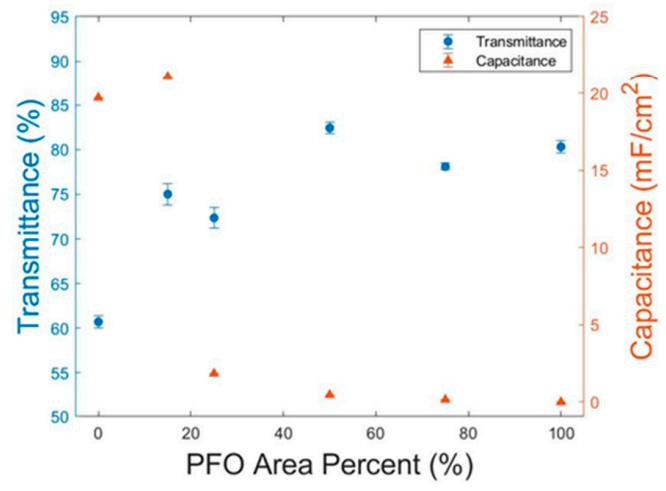

b)

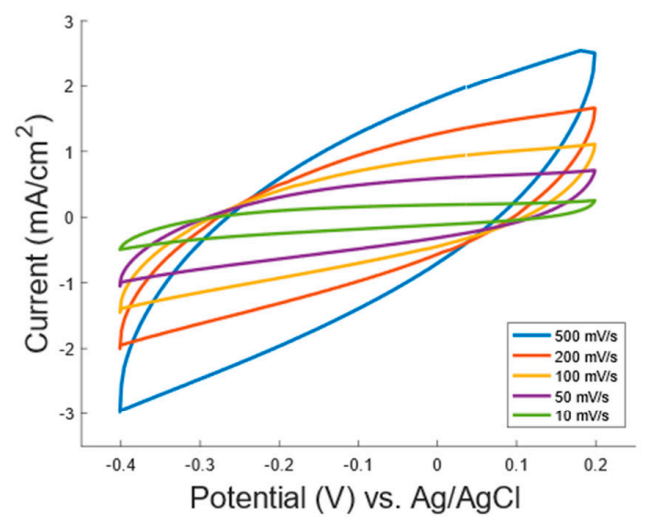

Figure 2. (a) Double $\mathrm{Y}$ plot comparing film transmittance and capacitance as a function of the composition of the RIR-MAPLE target. Error bars are included for transmittance measurements; however, error for capacitance measurements are too insignificant to include ( $<0.5 \%$ of average); (b) cyclic voltammogram (CV) curves of P15M85 electrode across multiple sweep rates in $0.5 \mathrm{M} \mathrm{Na}_{2} \mathrm{SO}_{4}$ with a $\mathrm{Ag} / \mathrm{AgCl}$ reference electrode.

Figure 3 compares the reported areal capacitances for 10 different material systems, including this work, demonstrating that the MXene/PFO composite system enabled by RIR-MAPLE deposition possesses good optical characteristics for application in transparent energy storage. A picture of the P15M85 electrode is shown in the inset to Figure 3 demonstrating its transparency. The transmittance for this film composition of a transparent supercapacitor electrode is among the best reported in literature, to the best of our knowledge. 


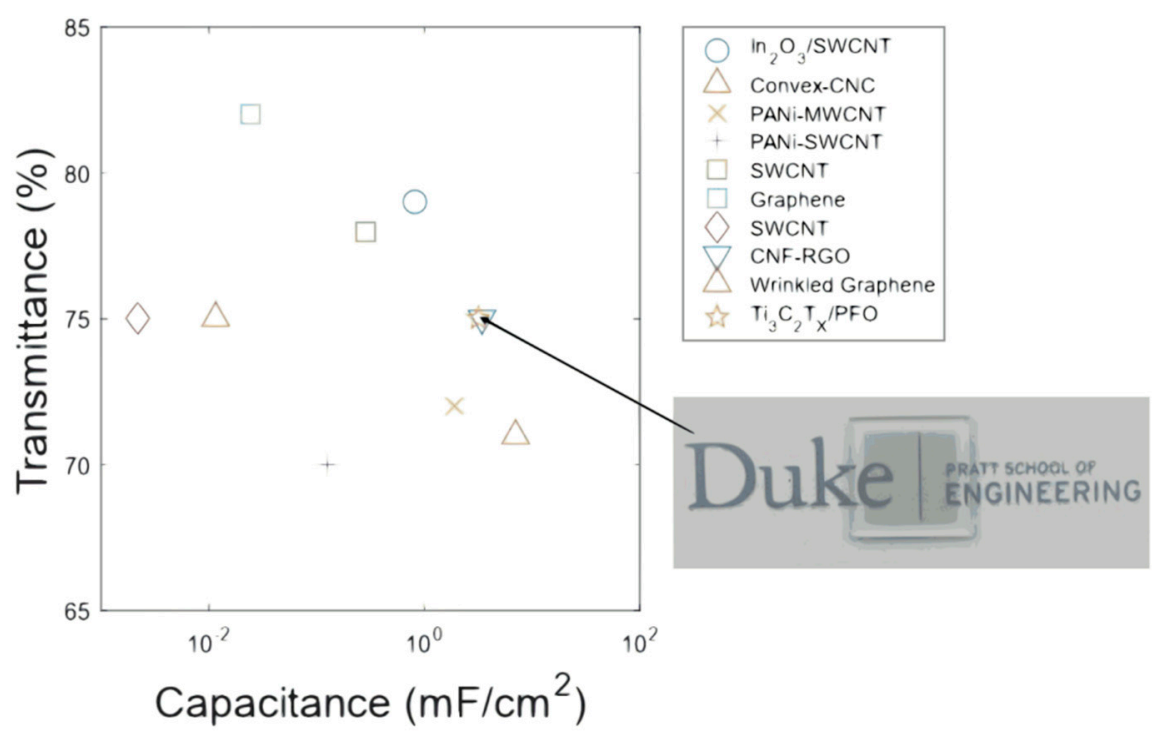

Figure 3. Comparison of areal capacitances for various material systems reported in the literature [30-38]. Inset: picture of P15M85 film on a $1 \mathrm{~cm} \times 1 \mathrm{~cm}$ glass substrate, indicating its high transparency.

\section{Conclusions}

Through the use of RIR-MAPLE, a novel composite structure was fabricated in which MXene flakes were embedded in a PFO polymer matrix. The resulting composite films have a higher areal capacitance with an increasing presence of MXene but decreased transmittance. The ability to control the electrode composition and to deposit a composite film with nanoscale blending or organic and inorganic components allowed for an increase in the transparency of the electrodes without significant changes in electrochemical performance (areal capacitances of $>20 \mathrm{mF} / \mathrm{cm}^{2}$ at $>75 \%$ transmittance). These findings open new avenues for further investigation into composite materials that can be created using the RIR-MAPLE technique. Such avenues include the following: i) binary, ternary, and quaternary material systems; ii) controlled surface morphology by deposition conditions; iii) deposition onto non-planar substrates; and iv) patterned area deposition. Thus, RIR-MAPLE is a promising deposition technique for constructing tailored composite energy electrodes.

Supplementary Materials: The following are available online at http://www.mdpi.com/2073-4352/10/3/152/s1, Figure S1: Transmittance plotted against wavelength for the full visible light spectrum. Two measurements were taken for each sample, one indicated as a solid line and the other dashed. PFO shows a large absorbance at $400 \mathrm{~nm}$ and a shoulder at $430 \mathrm{~nm}$ which indicates the presence of a crystalline phase of the polymer. A pure MXene film yields the lowest overall transmittance which increases with the addition of PFO.

Author Contributions: Conceptualization, J.O.T., C.B.P., J.T.G. and A.D.S.-R.; investigation, A.A., S.F. and E.N. writing-original draft preparation, A.A. and S.F.; writing-review and editing, J.O.T., E.N., C.B.P., J.T.G. and A.D.S.-R.; project administration, C.B.P., J.T.G. and A.D.S.-R.; funding acquisition, J.T.G. and A.D.S.-R. All authors have read and agreed to the published version of the manuscript.

Funding: This work was partially supported by Award ECCS-1344745 from the National Science Foundation.

Acknowledgments: The authors would like to acknowledge Mariana Vasquez-Sanchez for her insight into the potential application of RIR-MAPLE to deposit MXenes for transparent supercapacitor electrodes. They would also like to thank the Shared Materials Instrumentation Facility at Duke University for assistance in the physical characterization of electrodes.

Conflicts of Interest: The authors declare no conflict of interest.

\section{References}

1. Zhang, C.; Higgins, T.M.; Park, S.H.; O’Brien, S.E.; Long, D.; Coleman, J.N.; Nicolosi, V. Highly flexible and transparent solid-state supercapacitors based on RuO2/PEDOT:PSS conductive ultrathin films. Nano Energy 2016, 28, 495-505. [CrossRef] 
2. Kurlyandskaya, G.V.; Fernández, E.; Svalov, A.; Burgoa Beitia, A.; García-Arribas, A.; Larrañaga, A. Flexible thin film magnetoimpedance sensors. J. Magn. Magn. Mater. 2016, 415, 91-96. [CrossRef]

3. Zhang, C.; Nicolosi, V. Graphene and MXene-based transparent conductive electrodes and supercapacitors. Energy Storage Mater. 2019, 16, 102-125. [CrossRef]

4. King, P.J.; Higgins, T.M.; De, S.; Nicoloso, N.; Coleman, J.N. Percolation Effects in Supercapacitors with Thin, Transparent Carbon Nanotube Electrodes. ACS Nano 2012, 6, 1732-1741. [CrossRef] [PubMed]

5. Higgins, T.M.; Coleman, J.N. Avoiding Resistance Limitations in High-Performance Transparent Supercapacitor Electrodes Based on Large-Area, High-Conductivity PEDOT:PSS Films. ACS Appl. Mater. Interfaces 2015, 7, 16495-16506. [CrossRef] [PubMed]

6. Chen, P.; Zhou, C.; Chang, H.; Shen, G.; Ishikawa, F.N.; Ryu, K.; Badmaev, A.; Gomez De Arco, L. Transparent Electronics Based on Transfer Printed Aligned Carbon Nanotubes on Rigid and Flexible Substrates. ACS Nano 2008, 3, 73-79.

7. Ju, S.; Facchetti, A.; Xuan, Y.; Liu, J.; Ishikawa, F.; Ye, P.; Zhou, C.; Marks, T.J.; Janes, D.B. Fabrication of fully transparent nanowire transistors for transparent and flexible electronics. Nat. Nanotechnol. 2007, 2, 378-384. [CrossRef]

8. Anasori, B.; Gogotsi, Y.; Nicolosi, V.; Zhang, C.J.; Seral-Ascaso, A.; Coleman, J.N.; Park, S.-H.; Duesberg, G.S.; Shmeliov, A.; McEvoy, N. Transparent, Flexible, and Conductive 2D Titanium Carbide (MXene) Films with High Volumetric Capacitance. Adv. Mater. 2017, 29, 1702678.

9. Gupta, A.; Akhtar, A.J.; Saha, S.K. In-situ growth of P3HT/graphene composites for supercapacitor application. Mater. Chem. Phys. 2013, 140, 616-621. [CrossRef]

10. Stiff-Roberts, A.D.; Ge, W. Organic/hybrid thin films deposited by matrix-assisted pulsed laser evaporation (MAPLE). Appl. Phys. Rev. 2017, 4, 041303. [CrossRef]

11. Pate, R.; Lantz, K.R.; Stiff-Roberts, A.D. Tabletop resonant infrared matrix-assisted pulsed laser evaporation of light-emitting organic thin films. IEEE J. Sel. Top. Quantum Electron. 2008, 14, 1022-1030. [CrossRef]

12. Pate, R.; Lantz, K.R.; Stiff-Roberts, A.D. Resonant infrared matrix-assisted pulsed laser evaporation of CdSe colloidal quantum dot/poly[2-methoxy-5-(2'-ethylhexyloxy)-1,4-(1-cyano vinylene)phenylene] hybrid nanocomposite thin films. Thin Solid Films 2009, 517, 6798-6802. [CrossRef]

13. Pate, R.; McCormick, R.; Chen, L.; Zhou, W.; Stiff-Roberts, A.D. RIR-MAPLE deposition of conjugated polymers for application to optoelectronic devices. Appl. Phys. A Mater. Sci. Process. 2011, 105, 555-563. [CrossRef]

14. Ge, W.; Li, N.K.; McCormick, R.D.; Lichtenberg, E.; Yingling, Y.G.; Stiff-Roberts, A.D. Emulsion-Based RIR-MAPLE Deposition of Conjugated Polymers: Primary Solvent Effect and Its Implications on Organic Solar Cell Performance. ACS Appl. Mater. Interfaces 2016, 8, 19494-19506. [CrossRef] [PubMed]

15. McCormick, R.D.; Lenhardt, J.; Stiff-Roberts, A.D. Effects of emulsion-based resonant infrared matrix assisted pulsed laser evaporation (RIR-MAPLE) on the molecular weight of polymers. Polymers 2012, 4, 341-354. [CrossRef]

16. Ge, W.; Hoang, T.B.; Mikkelsen, M.H.; Stiff-Roberts, A.D. RIR-MAPLE deposition of plasmonic silver nanoparticles. Appl. Phys. A Mater. Sci. Process. 2016, 122, 1-6. [CrossRef]

17. Rella, R.; Cozzoli, P.D.; Arima, V.; Taurino, A.; Tunno, T.; Cesaria, M.; Catalano, M.; Martino, M.; Zacheo, A.; Caricato, A.P.; et al. MAPLE deposition of nanomaterials. Appl. Surf. Sci. 2013, 302, 92-98.

18. Ge, W.; Atewologun, A.; Stiff-Roberts, A.D. Hybrid nanocomposite thin films deposited by emulsion-based resonant infrared matrix-assisted pulsed laser evaporation for photovoltaic applications. Org. Electron. Phys. Mater. Appl. 2015, 22, 98-107. [CrossRef]

19. Stiff-Roberts, A.D.; Dunlap-Shohl, W.A.; Mitzi, D.B.; Gundogdu, K.; Barrette, A.; Barraza, E.T. MAPbI 3 Solar Cells with Absorber Deposited by Resonant Infrared Matrix-Assisted Pulsed Laser Evaporation. ACS Energy Lett. 2017, 3, 270-275.

20. Barraza, E.T.; Dunlap-Shohl, W.A.; Mitzi, D.B.; Stiff-Roberts, A.D. Deposition of Methylammonium Lead Triiodide by Resonant Infrared Matrix-Assisted Pulsed Laser Evaporation. J. Electron. Mater. 2018, 47, 917-926. [CrossRef]

21. Lukatskaya, M.R.; Dall'Agnese, Y.; Naguib, M.; Barsoum, M.W.; Ren, C.E.; Mashtalir, O.; Simon, P.; Taberna, P.L.; Gogotsi, Y.; Rozier, P. Cation Intercalation and High Volumetric Capacitance of Two-Dimensional Titanium Carbide. Science 2013, 341, 1502-1505. [CrossRef] [PubMed] 
22. Taberna, P.-L.; Dall'Agnese, Y.; Gogotsi, Y.; Simon, P.; Rozier, P. Capacitance of two-dimensional titanium carbide (MXene) and MXene/carbon nanotube composites in organic electrolytes. J. Power Sources 2015, 306, 510-515.

23. Ghidiu, M.; Lukatskaya, M.R.; Zhao, M.-Q.; Gogotsi, Y.; Barsoum, M.W. Conductive two-dimensional titanium carbide 'clay' with high volumetric capacitance. Nature 2014, 516, 78-81. [CrossRef] [PubMed]

24. Ouisse, T.; Armand, M.; Kervella, Y.; Stéphan, O. Fully transparent, organic light-emitting electrochemical cells. Appl. Phys. Lett. 2002, 81, 3131-3133. [CrossRef]

25. Grell, M.; Bradley, D.D.C.; Ungar, G.; Hill, J.; Whitehead, K.S. Interplay of physical structure and photophysics for a liquid crystalline polyfluorene. Macromolecules 1999, 32, 5810-5817. [CrossRef]

26. Machida, K.; Suematsu, S.; Ishimoto, S.; Tamamitsu, K. High-Voltage Asymmetric Electrochemical Capacitor Based on Polyfluorene Nanocomposite and Activated Carbon. J. Electrochem. Soc. 2008, 155, A970. [CrossRef]

27. Ferguson, S.; Williams, C.V.; Mohapi, B.; Stiff-Roberts, A.D. Deposition of $\beta$-Polyfluorene by Resonant Infrared Matrix-Assisted Pulsed Laser Evaporation. J. Electron. Mater. 2019, 48, 3388-3398. [CrossRef]

28. Stoller, M.D.; Ruoff, R.S. Best practice methods for determining an electrode material's performance for ultracapacitors. Energy Environ. Sci. 2010, 3, 1294-1301. [CrossRef]

29. Ge, W.; Yu, Q.; López, G.P.; Stiff-Roberts, A.D. Antimicrobial oligo(p-phenylene-ethynylene) film deposited by resonant infrared matrix-assisted pulsed laser evaporation. Colloids Surf. B Biointerfaces 2014, 116, 786-792. [CrossRef]

30. Niu, Z.; Zhou, W.; Chen, J.; Feng, G.; Li, H.; Hu, Y.; Ma, W.; Dong, H.; Li, J.; Xie, S. A Repeated Halving Approach to Fabricate Ultrathin Single-Walled Carbon Nanotube Films for Transparent Supercapacitors. Small 2013, 9, 518-524. [CrossRef]

31. Chen, T.; Xue, Y.; Roy, A.K.; Dai, L. Transparent and stretchable high-performance supercapacitors based on wrinkled graphene electrodes. ACS Nano 2014, 8, 1039-1046. [CrossRef]

32. Gao, K.; Shao, Z.; Wu, X.; Wang, X.; Zhang, Y.; Wang, W.; Wang, F. Paper-based transparent flexible thin film supercapacitors. Nanoscale 2013, 5, 5307. [CrossRef] [PubMed]

33. Sorel, S.; Khan, U.; Coleman, J.N. Flexible, transparent dielectric capacitors with nanostructured electrodes. Appl. Phys. Lett. 2012, 101, 103106. [CrossRef]

34. Gao, Y.; Zhou, Y.S.; Xiong, W.; Jiang, L.J.; Mahjouri-samani, M.; Thirugnanam, P.; Huang, X.; Wang, M.M.; Jiang, L.; Lu, Y.F. Transparent, flexible, and solid-state supercapacitors based on graphene electrodes. APL Mater. 2013, 1, 012101. [CrossRef]

35. Ge, J.; Cheng, G.; Chen, L. Transparent and flexible electrodes and supercapacitors using polyaniline/single-walled carbon nanotube composite thin films. Nanoscale 2011, 3, 3084. [CrossRef]

36. Lin, H.; Li, L.; Ren, J.; Cai, Z.; Qiu, L.; Yang, Z.; Peng, H. Conducting polymer composite film incorporated with aligned carbon nanotubes for transparent, flexible and efficient supercapacitor. Sci. Rep. 2013, 3, 1353. [CrossRef] [PubMed]

37. Jung, H.Y.; Karimi, M.B.; Hahm, M.G.; Ajayan, P.M.; Jung, Y.J. Transparent, flexible supercapacitors from nano-engineered carbon films. Sci. Rep. 2012, 2, 773. [CrossRef]

38. Chen, P.-C.; Shen, G.; Sukcharoenchoke, S.; Zhou, C. Flexible and transparent supercapacitor based on $\mathrm{In}_{2} \mathrm{O}_{3}$ nanowire/carbon nanotube heterogeneous films. Appl. Phys. Lett. 2009, 94, 43113-264104. [CrossRef]

(C) 2020 by the authors. Licensee MDPI, Basel, Switzerland. This article is an open access article distributed under the terms and conditions of the Creative Commons Attribution (CC BY) license (http://creativecommons.org/licenses/by/4.0/). 